\title{
Enhorabuena. La Licenciatura en Historia del Arte
}

L

a Universidad Nacional Autónoma de México (unam) ha abierto la carrera número ioo dentro del abanico de opciones profesionales que ofrece al pueblo de México. Se trata de una licenciatura en Historia del Arte que se impartirá en la Escuela Nacional de Estudios Superiores (ENES) de la ciudad de Morelia. El objetivo de esta nueva carrera es formar profesionistas que atiendan dos graves problemas planteados por el crecimiento del país: uno, la protección del patrimonio cultural; el otro, la investigación y difusión del mismo.

México no es una potencia industrial, aunque tal vez llegue a serlo en algún momento. Pero es una nación de grandes recursos naturales y un enorme patrimonio histórico y artístico. Luego, el conocimiento y la salvaguarda de este patrimonio obligan a formar cuadros especializados que cumplan esta misión. Otras instituciones, como el Instituto Nacional de Antropología e Historia, han asumido esta responsabilidad, pero la magnitud de nuestros bienes culturales requiere la intervención de otras entidades.

Actualmente existen centros y universidades privadas donde ya se hacen estudios de arte en el nivel de licenciatura, pero sus cuotas y colegiaturas son tan elevadas que resultan inaccesibles para la mayoría de la población. Toca a las instituciones públicas, particularmente a la UNAM, por su generosa condición de ser laica, gratuita y abierta a todos, sin más requisitos que la vocación y el talento, asumir esta responsabilidad social e histórica. Por algo es la universidad de la nación. 
En la historia de la educación y la cultura, las instituciones oficiales han sido un factor insustituible. La Real Academia de Bellas Artes de San Carlos, fundada por Carlos III en I783, se constituyó como el órgano rector e impulsor de la arquitectura y las bellas artes, por muchos años. En I867 la Ley Orgánica para la Instrucción Pública en el Distrito Federal, del gobierno juarista, reorganizó toda la educación, desde la primaria hasta la superior, como un supuesto indispensable para el Estado liberal y democrático nacido de la Constitución de 1857. En 1910, al quedar constituida, la Universidad Nacional acogió a la Escuela Nacional de Bellas Artes como parte integrante de lo que sería la máxima casa de estudios. En 1936 se creó el Instituto de Investigaciones Estéticas para llenar el vacío que había en la tarea de investigar el arte nacional. Ahora, aprobada por el Consejo Universitario en agosto de 20I2, se inicia la Licenciatura en Historia del Arte como una nueva opción para el pueblo de México y una respuesta para proteger nuestro patrimonio artístico, impulsando este campo esencial de las humanidades que es la historia del arte.

Eduardo BÁEz M.

El año pasado, el H. Consejo Universitario de la Universidad Nacional Autónoma de México (UNAM) aprobó el plan de estudios de la Licenciatura en Historia del Arte que se impartirá en la Escuela Nacional de Estudios Superiores, Unidad Morelia. En febrero de 2013, el mismo plan de estudios fue adoptado por unanimidad por el $\mathrm{H}$. Consejo Universitario de la Universidad Autónoma Benito Juárez de Oaxaca, para impartirse en el Instituto de Humanidades de esa institución hermana, con la asesoría del Instituto de Investigaciones Estéticas. Dicho plan fue redactado por una comisión de investigadores del Instituto de Investigaciones Estéticas y estudiantes del Posgrado en Historia del Arte que concluyeron el trabajo respectivo en poco menos de un año, logrando la aprobación colegiada en un año y medio.

Es poco usual que un instituto de investigación se ocupe de organizar estudios de licenciatura (pregrado en otros países de habla hispánica; B.A. en el sistema estadounidense, lo que se cursa después del bachillerato y antes del posgrado). Ninguna universidad pública mexicana ofrecía estudios de historia del arte en licenciatura hasta 201 I, aunque sí había programas en universidades privadas. 
Los motivos académicos de esta larga renuencia están claros. En la Facultad de Filosofía y Letras de la UnAm se estableció, muy temprano en el siglo $\mathrm{xx}$, una carrera de Historia de corte historicista, aunque ecléctico. Estos estudios combinaron herencias que pueden parecer dispares: un hegelianismo muy pronunciado, acompañado por una fascinación por las ideas de Martin Heidegger, propagada en parte por un profesor del exilio republicano español: José Gaos. Por si esto fuera poco, los fundadores de la tradición historicista mexicana tenían una aguda sensibilidad poética. Justino Fernández y Edmundo O’Gorman publicaron, en la editorial Alcancía, la primera versión que se conoció de Poeta en Nueva York, de Federico García Lorca, y también la primera edición de Orbe, de Juan Larrea. Eran lectores de Ortega, Croce y Dilthey y desconfiaban de los proyectos positivistas de ciencia social.

Quizá por esto último promovieron, como compensación, una historia del arte que fue en gran medida una historia social, política e ideológica. La tradición mexicana de estudios sobre arte es un discurso acerca de la articulación entre las imágenes o los objetos y las ideas vigentes en las sociedades. Seguramente esta "historia social historicista del arte", si es que esta expresión tiene validez, podrá explicarse porque el historicismo debió compartir los mismos espacios escolares y de investigación universitarios con una sólida corriente marxista, también alimentada por el exilio español.

Esta forma de organización tenía una enorme densidad intelectual, y por eso fue muy longeva. Tiene sus ventajas que un estudiante de segundo semestre sea obligado a leer la Filosofía de la historia de Hegel. Desde el punto de vista de la historia del arte, sin embargo, había también grandes carencias. Esos estudiantes, duchos en la lectura de los textos de filosofía de la historia de Kant (y sobre todo Si el género humano se encuentra en camino hacia mejor), lo ignoraban todo acerca de la fenomenología y la Crítica del juicio, dos pilares del pensamiento sobre las artes de los siglos XIX y Xx. Muy familiarizados con Gianbattista Vico, desconocían a Lessing y a Winckelmann. Todos tenían un punto de vista sobre Spengler, pero no habían oído hablar de Wölfflin y Worringer. Estaban y están entrenados en forma admirable para el comentario de textos escritos, pero sus herramientas para el comentario de las imágenes no eran suficientes.

La inexistencia de una licenciatura puede explicar además una conformación sui generis de la historia del arte en México y en la unAM. Las historias generales, que normalmente se escriben con fines de docencia, han sido pocas. Los estudios y las investigaciones se orientan en forma casi exclusiva al arte nacional. 
Sigue teniendo vigencia una "filosofía de la historia" muy siglo xIx. Se necesitará mucha creatividad académica para no perder la indudable riqueza que tenía esa conformación. Los análisis de la articulación entre las artes, la política y la sociedad se hacían desde una posición sofisticada y llena de matices (los historiadores del arte, que se apoyan en la polisemia de las imágenes, no siempre aceptan la multitud de dimensiones en la política y la sociedad). Este movimiento hacia la disciplina se lleva a cabo cuando en todo el mundo hay colegas que caminan en sentido contrario, a través de los estudios de la imagen, hacia un sitio próximo al de los fundadores de nuestro Instituto: una confluencia de investigaciones sociales y culturales a partir del análisis de las imágenes.

La UNAM apoya su docencia en las licenciaturas de humanidades en una tradición universitaria latinoamericana muy liberal que se originó, en los años diez del siglo xx, en la reforma universitaria argentina: los estudiantes tienen libertades para elegir a sus maestros y para participar en la vida académica; se espera que participen activamente en su propia formación, hagan investigaciones y tengan debates académicos a lo largo de su formación básica. La elaboración y aprobación de la nueva licenciatura significa que serán ellas y ellos quienes resuelvan las opciones intelectuales y éticas de la disciplina. Se ha buscado ofrecerles las mejores herramientas posibles para esa renovación permanente. Es obvio que, con ello, aspiramos a nuestra propia renovación.

Renato GonzÁlez Mello

A finales de agosto de 2012, el Consejo Universitario de nuestra casa de estudios aprobó la creación de la Licenciatura en Historia del Arte, la cual será impartida en la Escuela Nacional de Estudios Superiores, Unidad Morelia, en Michoacán. La instauración de dicho grado resulta de particular relevancia y valor dentro del contexto actual tanto de la disciplina como de la educación en México, por razones de muy diversa índole. Quisiera esbozar brevemente algunas que, a mi parecer, revisten una excepcional importancia.

La puesta en marcha de esta licenciatura constituye el punto culminante dentro del proceso de profesionalización de la historia del arte en el país. Como se recordará, la Universidad Nacional Autónoma de México fue pionera en dicha labor al crearse, en 1935, el Laboratorio de Arte y, en 1936, el Instituto de Investigaciones Estéticas. Ofreciendo desde la segunda mitad de los años 
treinta estudios de posgrado en la materia —originalmente dentro de otros programas impartidos en la Facultad de Filosofía y Letras-, se llevaron a cabo sucesivamente la especialidad, la maestría y el doctorado, y posteriormente se instituyó el Posgrado en Historia del Arte.

La creación de la Licenciatura en Historia del Arte se suma al trabajo y las aportaciones de nuestra institución en cuanto al desarrollo de este campo de estudios. Al ser la primera carrera en la materia impartida en una universidad pública mexicana, responde a necesidades concretas relacionadas con demandas y retos específicos del contexto y el estado actual de los estudios y la práctica profesional de la disciplina en nuestro país.

El plan de estudios fue elaborado cuidadosamente por distinguidos investigadores del Posgrado en Historia del Arte — proceso en el cual tuve la fortuna de participar durante la etapa de análisis y fundamentación del primer borrador. Por su composición, promueve y contempla una formación integral e interdisciplinaria, excepcional dentro de la oferta educativa nacional en historia del arte en el nivel de estudios superiores.

La carga curricular encaminada al aprendizaje teórico-metodológico y práctico específico de la disciplina incluye asignaturas orientadas hacia el desarrollo de herramientas analíticas y de investigación del arte mexicano y mundial, así como conocimientos y habilidades de comprensión y gestión del patrimonio tanto material como simbólico.

Asimismo, el programa destaca la formación plural y humanística en la amplia oferta de materias de otras áreas de conocimiento. También comprende el aprendizaje de lenguas desde una perspectiva de profundización, inexistente en licenciaturas análogas, herramienta de gran utilidad para cualquier egresado.

A la par, contempla asignaturas y la posibilidad de especialización en ámbitos de estudio y discusiones epistemológicas de suma actualidad, como los estudios de la imagen, la cultura visual y el problema de la representación. Además, incluye optativas que responden a la demanda creciente y el interés por el análisis y la investigación especializados en artes como la música, el cine y la fotografía, así como coloquios semestrales para promover el intercambio intelectual con los pares y la adquisición de habilidades de comunicación.

La Licenciatura en Historia del Arte otorga el título de Licenciado en Historia del Arte — con área de profundización en arte mexicano o en iconografía y estudios de la imagen - y el diploma de Técnico en Gestión y Difusión del Patrimonio Artístico. El primero requiere cursar los ocho semestres del plan, y el segundo puede obtenerse al finalizar los primeros cuatro. 
La existencia de este programa, por tanto, puede estimular en los jóvenes la inquietud por el estudio de la disciplina, en tanto ofrece posibilidades de profesionalización en todo nivel orientadas hacia un extenso abanico de ámbitos profesionales.

Por una parte, al ponerse en marcha se afina y complementa la labor de nuestra universidad en la formación de investigadores y docentes especializados en la materia, así como su reconocimiento y desarrollo en el ámbito académico.

De igual manera, se contribuye a subsanar las problemáticas relativas a la conservación, el estudio y la difusión del patrimonio artístico y cultural de México. Sabido es que nuestro país cuenta con un conjunto patrimonial de enorme riqueza cuya preservación, investigación y promoción requiere un arduo trabajo especializado y en constante impulso. Hoy día esta empresa se ve dificultada por el reducido número de profesionistas capacitados para ello.

También se continúa y fomenta el trabajo de profesionalización de especialistas facultados para desenvolverse en esferas y espacios de la vida cultural relacionados con el arte (crítica, catalogación, curaduría, edición, museos, galerías, instituciones culturales, acervos, gestión y desarrollo de políticas, entre otros).

La institucionalización de la carrera y de un espacio y formación específicos permitirá fomentar una vida cultural de mayor profesionalización. De esa manera se favorecerá la superación de las tendencias a trivializar y a los lugares comunes y superficiales de la historia del arte en México.

Finalmente cabe destacar que, al radicarse la Licenciatura en Historia del Arte en Michoacán — uno de los estados con mayor riqueza artística y cuna de espacios imprescindibles para nuestra vida cultural, como el Conservatorio de las Rosas y el Festival Internacional de Cine de Morelia-, se impulsa y da continuidad al esfuerzo por descentralizar los espacios y recintos de producción del saber, todo ello bajo el principio de la educación al alcance de las mayorías, uno de los pilares esenciales de nuestra casa de estudios, cuyo valor es evidente dentro del contexto mundial actual y las tendencias globales de privatización de la educación.

\section{Dulce Isabel Aguirre Barrera}

Mucho discutían los estudiantes de Historia, en los pasillos de la Facultad de Filosofía y Letras de la Universidad Nacional Autónoma de México, sobre la 
pertinencia de que nuestras autoridades universitarias se plantearan la creación de una licenciatura en historia del arte. Se debatía entonces, cuando yo comenzaba mi formación, y es muy probable que se haya seguido discutiendo durante todos los años anteriores a la decisión del Consejo Universitario de crearla finalmente.

La charla era obligada sobre todo durante los periodos de inscripción en los que estudiábamos panorámicamente las asignaturas del plan de estudios, entre las cuales había una buena selección de materias de arte para elegir. La idea de continuar desde un tronco común hacia el itinerario de la historia del arte — como lo que ya existía-, o bien, la posibilidad de comenzar a andar desde un principio por ese sendero (para muchos, el camino de la historia del arte era una elección tomada desde el comienzo), se convertían en los dos polos principales de la discusión.

Desde el punto de vista de quienes habían iniciado la licenciatura en historia con la idea clara de que su objeto de estudio estaría relacionado con el fenómeno artístico, parecía pertinente la existencia de una opción que priorizara sus intereses y no los "obligara" a inscribir materias sobre temáticas poco atractivas para ellos. En opinión de quienes habíamos entrado en la licenciatura sin un tema u objeto de estudio particular - y que agradecíamos el hecho de que, gracias a la amplia oferta de asignaturas, nuestros profesores nos hubieran guiado hacia sus propios itinerarios temáticos_- la idea de una carrera sin esa oferta panorámica de la cual nos habíamos beneficiado no nos parecía tan buena.

Carecer de un objeto de estudio definido previa o tempranamente no anulaba las posibilidades de quienes a mitad de carrera ya habían sido seducidos por algunos profesores con teorías sobre la recepción del arte o el análisis de la imagen y finalmente decidían escribir una tesis sobre algún tema de historia del arte. A partir de los seminarios, todos ellos de carácter obligatorio-electivo — es decir: había que cursarlos pero existía oferta temática-, muchos de quienes no creíamos en la necesidad de una licenciatura en historia del arte decidimos tomar ese camino después de la segunda mitad de la carrera. En quinto semestre, habiendo cursado casi todas las materias formativas del área teórica y práctica, aún había tiempo para inscribir materias de arte no sólo entre las correspondientes al área obligatoria de "conocimiento histórico" sino también materias "optativas libres de restricción”, esto es, asignaturas que no debían ceñirse a ninguna de las cuatro subáreas obligatorias. En otras palabras, habiendo cursado media carrera, e incluso sin haber inscrito materias optativas del área histórico-artística, aún cabía la posibilidad de virar de la historia "a secas” a la historia del arte. 
En aquel entonces, quienes no abogaban por una licenciatura diseñada para unos cuantos privilegiados que ya sabían a qué querían dedicarse se preguntaban si asignaturas como teoría de la historia, filosofía de la historia e incluso introducción a la historia tendrían prioridad o siquiera espacio en un hipotético currículum de historia del arte en el nivel licenciatura. Todos coincidíamos en que debería ser así. En el plan de estudios de historia se privilegiaban tanto el área de teoría como el área de conocimientos básicos de metodología de la investigación y docencia, otorgándoles casi 40 por ciento de la carga académica en la licenciatura. Otras ocho materias obligatorias —o I 3 por ciento del total pero con el doble de créditos- estaban destinadas a hacer que los futuros historiadores aprendiéramos sobre la historia de la historia. Y entonces cabía preguntarse: ¿qué historiografía se enseñaría en historia del arte?

Si por historiografía del arte entendíamos los textos producidos a lo largo del tiempo en relación estricta y particular con la materia de estudio de los historiadores del arte, o bien, el estudio crítico de dichos textos, ¿`ignificaba que las clases de historiografía omitirían a Herodoto, Tucídides y Tito Livio? Para algunos era impensable.

Por otra parte, convencer a los reticentes suponía, para los convencidos, aportar pruebas en favor de que la historia del arte no era — como sí lo eran la historia económica, política, cultural y social, entre otras - un enfoque historiográfico o un estudio histórico realizado a la luz de ciertas temáticas. A la historia del arte le correspondía, según sus defensores, un estatus igualitario respecto a la historia a secas. Es decir, le correspondía atender sus propios problemas como disciplina autónoma.

Independientemente de los intereses particulares de estudio que tuviera y del apellido que eligiera, un historiador debería haber aprendido durante su formación básica no sólo a interrogar fuentes de diversos tipos; también debía poseer un panorama historiográfico de la mayor cantidad de periodos históricos para poder hacer preguntas coherentes con sus fuentes. Además, debía tener una idea clara de la importancia de su labor y, a la manera de algunas disciplinas como la medicina o la antropología, poseer una especie de código deontológico que definiera responsablemente su actividad académica. Estas premisas, sin duda, unificaban las opiniones de quienes estaban a favor de la creación de la licenciatura y de quienes no lo estaban.

Al día de hoy, siendo una realidad la carrera de historia del arte, todavía parece mantenerse vigente la discusión, si no en el seno de los órganos de go- 
bierno de nuestra universidad, sí entre quienes habíamos dejado algunas horas de cavilaciones en la facultad.

Revisando el plan de estudios de la Licenciatura en Historia del Arte, aprobada por unanimidad en la sesión del 24 de agosto de 2012 del Consejo Universitario, la cual será impartida en la Escuela Nacional de Estudios Superiores de Morelia, queda claro que la realidad superó nuestras reflexiones de pasillo y sobre la mesa hoy encontramos muchos más aspectos sobre los cuales discutir.

Sí, se echan de menos materias formativas como la filosofía y la teoría de la historia; de igual modo, se echan en falta las historiografías generales y la introducción a la disciplina. Incluso aún existen pocas opciones para complementar la carga obligatoria de la carrera, aunque quizá esto sólo sea una cuestión de tiempo. Sin embargo, vale la pena seńalar algunas alternativas incluidas en el plan de estudios a la luz de ciertas necesidades que no parecían ser primordiales entre los historiadores en formación en México hace unos Is años.

Nuestras discusiones estudiantiles se centraban en la historia del arte como la disciplina cuyo campo de estudio era el hecho artístico en su dimensión histórica; las obras de arte, sus análisis de forma y sus procesos de producción y recepción. Hoy, las tareas de difusión, gestión y promoción del patrimonio artístico han cobrado gran importancia y se han convertido también en compromiso académico de los historiadores del arte. Es decir, las nociones de patrimonio, a su vez coincidentes con las de riqueza artística e identidad nacional, son ya parte de las problemáticas particulares de esta disciplina.

Nuestra formación técnica de historiadores abarcaba poco más que algún entrenamiento en la investigación paleográfica y archivística, pero ésta, aún pilar de muchos en su actividad profesional, resulta hoy insuficiente para un ámbito de la historia del arte enfocado en atender materias patrimoniales. Por supuesto, el de la gestión del patrimonio no es actualmente la única esfera de interés de la historia del arte, pero se ha convertido cada vez más en parte de su problemática cotidiana. Por tanto, un entrenamiento técnico en materia de restauración, curaduría, fundamentos museísticos, crítica y catalogación, o bien, conocimiento de los mercados y círculos del arte, ausente del todo en el mapa curricular de la licenciatura de historia, se ve hoy, a la luz de estas materias de trabajo particulares, como una necesidad formativa de aquellos historiadores del arte interesados en estas tendencias dentro de su disciplina. La nueva licenciatura de la ENES, Morelia, las ha priorizado en la carga académica de la primera mitad de la carrera. 
Tras dos años de estudio, es posible egresar con un diploma de Técnico en Gestión y Difusión del Patrimonio Artístico. Con ello queda claro que la carrera número Ioo de la UNAM buscó cubrir profesionalmente un hueco que dejaba la historia “a secas". Queda claro también que el hueco no abarcaba toda la esfera de intereses de la historia del arte, sino sólo las materias de gestión y difusión.

Es muy probable que de la licenciatura de historia sigan egresando jóvenes interesados en otras vertientes de la historia del arte y tengan acceso, desde allí, a los posgrados correspondientes para especializarse, a la manera (más) tradicional, en el arte como hecho histórico. En otras palabras, la creación de una licenciatura en historia del arte no anula las posibilidades de realizar el viraje antes mencionado: quienes comiencen su formación en historia y elijan un objeto de estudio del ámbito artístico seguirán teniendo ocasión de hacerlo y no hay razón para pensar que será una elección desafortunada. De otra manera no puede explicarse que muchos profesionales de hoy, compañeros en la licenciatura en historia, se hayan convertido en académicos comprometidos con su materia de trabajo y sí, en historiadores del arte en toda regla.

De la nueva carrera seguramente egresarán jóvenes con perfiles distintos, y, en ese sentido, la ventaja de la creación de esta nueva licenciatura consiste en que no reproduce las opciones actuales, las diversifica y proporciona opciones profesionales antes inexistentes en la universidad pública.

\section{María Xóchitl Galindo Villavicencio}

